\title{
Ice-sheet mass balance at the Last Glacial Maximum from the GENESIS version 2 global climate model
}

\author{
Starley L. Thompson, David Pollard \\ Climate Change Research Section, Climate and Global Dynamics Division, National Center for Atmospheric Research, \\ Boulder, CO 80307, U.S.A.
}

\begin{abstract}
At the Last Glacial Maximum (LGM) about 21000 years ago (21 ka BP), the overall mass balance of the Laurentide and Eurasian ice sheets should have been close to zero, since their rate of change of total ice volume was approximately zero at that time. The surface mass balance should have been zero or positive to balance any iceberg/iceshelf discharge and basal melting, but could not have been strongly negative. In principle this can be tested by global climate model (GCM) simulations with prescribed ice-sheet extents and topography.

We describe results from a suite of $21 \mathrm{ka}$ BP simulations using a new GCM (GENESIS version 2.0.a), with sea-surface temperatures (SSTs) prescribed from GLIMAP (1981) and predicted by a mixed-layer ocean model, and with ice sheets prescribed from both the ICE-4G (Peltier, 1994) and CLIMAP (1981) reconstructions. This GCM is well suited for ice-sheet mass-balance studies because (i) the surface can be represented at a finer resolution than the atmospheric GGM, (ii) an elevation correction accounts for spectral distortions of the atmospheric GCM topography, (iii) a simple post-processing correction for the refreezing of meltwater is applied, and (iv) the model's precipitation and mass balances for present-day Greenland and Antarctica are realistic. However, for all reasonable combinations of SSTs and ice-sheet configurations, the predicted annual surface mass balances of the LGM Laurentide and Eurasian ice sheets are implausibly negative. Possible reasons for this discrepancy are discussed, including increased ice-age aerosols, higher CLIMAP-like ice-sheet profiles in the few thousand years preceding the LGM, and a surface of the southern Laurentide just before the LGM to produce fleetingly the ICE-4G profile at $21 \mathrm{ka} B P$.
\end{abstract}

\section{INTRODUCTION}

During the last two decades many global climate models (GCMs) have been used to simulate the climate of the Last Glacial Maximum (LGM). In the last 5-10 years, however, all of the major boundary conditions that are prescribed for these simulations have been questioned or revised. The timing of the LGM as defined by $\delta^{18} \mathrm{O}$ deep-sea-core records has been revised from 21000 to 18000 years ago (Bard and others, 1990), thus changing the orbital elements with small, but perceptible, effects on climate simulations (Hyde and Peltier, 1993). The CंLIMAP (1981) ice-sheet reconstructions used until recently by most GGM simulations are being superceded by the more sophisticated reconstructions of Peltier (1994), whose ICE-4G Laurentide and Eurasian ice sheets are much thinner than those of CLIMAP. And since the mid-1980s, data have accumulated that question the relatively small $1-2^{\circ} \mathrm{C}$ cooling of tropical and subtropical seasurface temperatures estimated by the planktonic transferfunction techniques of CLIMAP (1981). This includes independent evidence of greater cooling on low-latitude land masses (e.g. Rind and Peteet, 1985) and at least one tropical sea-surface temperature (SST) site (Guilderson and others, 1994), suggesting cooling of $\sim 5^{\circ} \mathrm{C}$. The effects of these different SSTs and ice-sheet boundary conditions on LGM climate simulations are potentially significant, and are just beginning to be explored.
One fact concerning the LGM has not changed: about 21000 years ago (henceforth $21 \mathrm{ka} \mathrm{BP}$ ) the global ice volume as measured by deep-sea-core $\delta^{18} \mathrm{O}$ records reached a maximum value. This was preceded by at least 5000 years of strong positive global-ice growth, and succeeded by about 15000 years of overall rapid ice-melt during the last deglaciation (c.g. Imbrie and others, 1984; Shackleton, 1987). This is roughly consistent with terrestrial geologic records left by the Laurentide and Eurasian ice sheets, the southern margins of which, by and large, reached their maximum extents around that time (Denton and Hughes, 1981; Dyke and Prest, 1987; Ruddiman and Wright, 1987; Clark, 1994). The straightforward implication is that the net annual mass balance of ice sheets and glaciers worldwide was positive from at least $25-21 \mathrm{ka} \mathrm{BP}$, nearly zero for a period around $21 \mathrm{ka} \mathrm{BP}$, and became strongly negative shortly after $21 \mathrm{ka} \mathrm{BP}$.

In principle this provides a test of GCMs and the prescribed boundary conditions used to simulate the LGM climate. In those GCMs where the surface mass balance over all ice-sheet points is calculated, the global surface icesheet mass budget can be predicted. According to the above rationale, this value should be relatively small, or positive to balance basal melt and iceberg/ice-shelf discharge, but should not be strongly negative. If it were strongly negative, it would suggest either that the GCM physics is wrong, or that one or more of the boundary conditions used in the simulation (prescribed SSTs, prescribed icc-sheet extent 
and elevations, or atmospheric $\mathrm{CO}_{2}$ amount) are in error, and are producing too much melt and/or too little precipitation on the ice sheets. By "strongly negative", we mean values that would correspond to a global eustatic sea-level rise of $\sim 1 \mathrm{~cm} \mathrm{a}{ }^{-1}$ or more (a typical rate during the last deglaciation), or a complete wastage of individual ice sheets in less than $\sim 10000$ years.

In order for this test to be meaningful, the GGM physics involved in ice-sheet mass balance should be reasonably realistic, and the results for present-day ice sheets should be close to observed estimates. However, most previous GCM calculations of surface mass budgets for present-day Greenland have been severely in error, mainly due to problems of scale and to the neglect of refreezing of meltwater. As described below, we have recently addressed these problems in a new version of the Global ENvironmental and Ecological Simulation of Interactive Systems (GENESIS) GCM, and have obtained good present-day simulations of the precipitation, ablation and mass balance on Greenland and Antarctica (Thompson and Pollard, 1997). The main purpose of this paper is to present LGM results using this GCM and various combinations of SSTs (predicted and prescribed) and ice-sheet prescriptions, focusing on the predicted mass balances of the Laurentide and Eurasian ice sheets, and to discuss the overall consistency of the results.

The next section outlines the formulation of the GENESIS GCM, and defines the experimental setup and boundary conditions used for the LGM simulations. The third section outlines the methods used to predict ice-sheet budgets in this GCM, and presents these budgets for various LGM simulations with predicted and prescribed SSTs and different ice-sheet reconstructions. It is found that, for all plausible combinations of boundary conditions, the predicted ice-sheet budgets appear to be too negative. Some of the consequences of this are discussed in the final section, including speculation on ice-sheet evolution in the several thousand years leading up to the LGM.

\section{GLOBAL GLIMATE MODEL DESGRIPTION}

The GCM used here is version 2.0.a of GENESIS (hereafter abbreviated to version 2). It has been developed at NGAR with emphasis on terrestrial, biophysical and cryospheric processes, for the purpose of performing greenhousc and paleoclimatic experiments. An earlier version (1.02) of the model with coarser atmospheric resolution has been described in Thompson and Pollard (1995a,b) and Pollard and Thompson $(1994,1995)$. Present-day results with version 2 are significantly improved over version 1.02 , and the new physics in version 2 and its present-day climate including Greenland and Antarctic mass balance is described in Thompson and Pollard (1997). More information on the global climate of the $21 \mathrm{ka}$ BP simulations is included in Pollard and Thompson (in press) and a further application coupled to a dynamic ice-sheet model is described in Pollard and Thompson (1997). For brevity, only a few basic features of the model are mentioned here; more complete descriptions are given in the above references.

The standard version-2 model consists of an atmospheric GCM (AGGM) coupled to multi-layer models of vegetation, soil or land ice, and snow. SSTs and sea ice are computed using a $50 \mathrm{~m}$ slab oceanic layer. The AGCM grid is independent of the surface grid, and fields are transferred between the AGCM and the surface by bi-linear interpolation (AGCM fields to surface) or straightforward area-averaging (surface fluxes to AGCM) at each time-step. The nominal AGGM resolution is spectral T31 $\left(\sim 3.75^{\circ} \times 3.75^{\circ}\right)$ with 18 vertical levels, and the surface grid used for all surface models is $2^{\circ} \times 2^{\circ}$, with an overall GCM time-step of 0.5 hours. These resolutions were used for the GCM experiments described below.

A land-surface transfer model (LSX) accounts for the physical effects of vegetation (Pollard and Thompson, 1995). Up to two vegetation layers ("trees" and "grass") can be specified at each grid point, and the radiative and turbulent fluxes through these layers to the soil or snow surface can be calculated. Vegetation attributes, such as leaf-area indices, fractional cover, leaf albedos, etc, are prescribed from present-day off-line results of a predictive naturalvegetation model (the $\mathrm{EVE}$ model; personal communication from J. C. Bergengren, 1996). No modifications to the present-day natural vegetation have been made for the $21 \mathrm{ka}$ BP experiments in this paper.

A 6-layer soil model extends from the surface to $4.25 \mathrm{~m}$ depth, with layer thicknesses increasing from $5 \mathrm{~cm}$ at the top to $2.5 \mathrm{~m}$ at the bottom. Physical processes in the vertical soil column include heat diffusion, liquid-water transport, surface runoff and bottom drainage, uptake of liquid water by plant roots for transpiration, and the freezing and thawing of soil ice. The same 6-layer model is used for ice-sheet surfaces, with physical parameters appropriate for ice, and with internal-liquid moisture. A 3-layer snow model is used for snow cover on soil, ice-sheet and sea-ice surfaces, including fractional areal cover when the snow is thin.

A 3-layer thermodynamic sea-ice model predicts the effect of local melting and freezing on the ice thickness and fractional areal coverage. Sea-ice advection is included using the "cavitating-fluid" model of Flato and Hibler (1992), using AGCM surface winds and prescribed ocean currents. The ocean is represented by a $50 \mathrm{~m}$ thick thermodynamic slab, which crudely captures the seasonal heat capacity of the surface-mixed layer. Oceanic heat transport is treated as horizontal diffusion down the gradient of the mixed-layer temperature, with the diffusion coefficient depending on latitude to produce roughly the present observed zonal-mean transport. A region of enhanced winter-flux convergence in the Norwegian Sea is specified that keeps the region ice-free, as observed for the present day, and an additive global adjustment is made at each time-step to ensure that the global integral of the convergence is zero.

\section{Present and 21 ka BP boundary conditions}

For all $21 \mathrm{ka}$ BP simulations described below, the land-ocean map was obtained from the $2^{\circ} \times 2^{\circ}$ CLIMAP (1981) dataset. For runs with ICE- $4 \mathrm{G}$ ice sheets, the ice-sheet extents and topography were prescribed from the $1^{\circ} \times 1^{\circ}$ ICE- $4 \mathrm{G}$ reconstruction of Peltier (1994), aggregated to our GCM's $2^{\circ} \times 2^{\circ}$ surface grid, and with ICE- $4 \mathrm{G}$ ice taking precedence over conflicting CLIMAP ocean points.

We will describe results mainly from two sets of modern and LGM simulations, one using the $50 \mathrm{~m}$ mixed-layer-slab ocean and dynamic sea-ice models, and the other using prescribed SSTs and sea ice. For the latter set, the $21 \mathrm{ka}$ BP SSTs were derived from the $2^{\circ} \times 2^{\circ}$ CLIMAP (1981) SSTand seaice maps for February and August, by fitting sinusoids in 
time between those two extreme months for each gridpoint, and using straighforward rules for the occurrence of sea ice in the intervening months. Prescribed SSTs for the present day were obtained from the climatological monthly SST and sea-ice $2^{\circ} \times 2^{\circ}$ dataset of Shea and others (1992). Both these prescribed SST datasets specify only the location of sea ice, so we set ice thicknesses and fractions simply to $1 \mathrm{~m}$ and 0.9 , respectively, in the Southern Hemisphere; in the Northern Hemisphere they were set to $1 \mathrm{~m}$ and 0.92 below $70^{\circ} \mathrm{N}$, and ramped linearly up to $4 \mathrm{~m}$ and 0.998 between $70^{\circ} \mathrm{N}$ and $90^{\circ} \mathrm{N}$.

The amounts of greenhouse trace gases were prescribed following guidelines of the Paleoclimatic Modeling Intercomparison Project (PMIP) (Joussaume and others, 1993) that are designed to ensure the same greenhouse radiative forcing between models. For present-day control runs the atmospheric $\mathrm{CO}_{2}$ concentration was set to $345 \mathrm{ppmv}$; for the prescribed SST LGM simulation it was 200 ppmv, and for the slab-ocean LGM simulation it was $246.4 \mathrm{ppmv}$. The rationale for the latter value involves lags between the equilibrated pre-industrial climate and the present climate ( 246.4 is $200 \times 345 / 280$, where 280 is roughly the pre-industrial value). Again following PMIP, the other model trace gases were unchanged from their present-day values: $\mathrm{CH}_{4}=1.653$ ppmv, $\mathrm{N}_{2} \mathrm{O}=0.306$ ppmv, $\mathrm{CFC}_{1 \mathrm{II}}=0.238 \mathrm{ppbv}$, and $\mathrm{CFC}_{12}=0.408 \mathrm{ppbv}$. The most appropriate choice of greenhouse-gas levels is a complicated issue, involving in part the transient response of the modern climate to greenhouse warming that is usually neglected in present-day "equilibrium" GCM experiments. In the future it would probably be better to use the actual observed amounts for paleoclimate experiments, and to account carefully for the disequilibrium in the present climate in the development of the present-day model.

The $21 \mathrm{ka}$ BP orbital elements used (Berger, 1978) were eccentricity $=0.018994$, obliquity $=22.949^{\circ}$, and precession $=114.42^{\circ}$ prograde from the Northern Hemispheric autumnal equinox to perihelion. All other prescribed parameters and fields in the model were unchanged from the present day, including atmospheric ozone distribution, gravity-wave surface roughness, soil textures, ocean currents under dynamic sea ice, and EVE vegetation distribution.

\section{ICE-SHEET BUDGETS}

The precipitation, melting and evaporation over the model ice sheets at the LGM are determined by the simulated climate, notably by storm tracks, surface-air temperatures, surface winds and cloudiness. These and other global-model fields for $21 \mathrm{ka}$ BP are described in Pollard and Thompson (in press), and compared in some detail with proxy data and results from other GCMs. For brevity, we will not reproduce these global climate results here, but concentrate instead on the mass balance over the ice sheets.

In order to test the GCM's predictions for LGM icesheet mass balance, the model physics involved in those processes must be reasonably realistic. However, there are two significant problems in using GGMs to predict massbalance distributions on ice sheets: (i) the relatively coarse GCM horizontal resolution truncates the topography of the ice-sheet flanks and smaller ice sheets such as Greenland, and to a lesser extent the Eurasian and the flanks of the Laurentide, and (ii) the snow and ice physics in most GCMs does not include ice-sheet-specific processes such as the refreezing of meltwater.

Due partly to these shortcomings, the simulated budgets of present-day Greenland and/or the LGM Laurentide and Eurasian ice sheets have been much too negative in many earlier coarse- and medium-resolution GCMs (Manabe and Broccoli, 1985; Rind, 1987; Broccoli and Manabe, 1993). In GENESIS version 2 two techniques are employed that attack these problems (Thompson and Pollard, 1997). For the scale problem, the AGCM meteorological fields passed to the ice-sheet surface model at each time-step are (i) interpolated to the $2^{\circ} \times 2^{\circ}$ surface grid as for all surface models, and (ii) corrected for the error between the AGCM spectrally truncated topography and the true $2^{\circ} \times 2^{\circ}$ topography, using simple adjustments based on a constant lapse rate of $-7.0^{\circ} \mathrm{C} \mathrm{km}^{-1}$. (This value is an estimate of the change in surface-air temperature that would result in a vertical shift of the large-scale surface itself; it has no obvious relationship to the free-air temperature profiles predicted by the GCM above the spectrally truncated surface.) Furthermore, a post-processing correction of the refreezing of meltwater is made to the annual history fields over ice sheets, following Pfeffer and others (1991); this parameterization reduces the account of local snow and ice-melt that becomes mobile enough to escape the ice sheet, depending on the ratio of the annual melt to the previous winter's snowpack. With these two corrections the model's precipitation, ablation and surface mass balances for present-day Greenland and Antarctica lie well within the mid-ranges of recent observed estimates (Warrick and Oerlemans, 1990; Van der Veen, 1991; Meier, 1993; Warrick and others, 1996; Thompson and Pollard, 1997), so we may expect the same techniques applied to the LGM ice sheets should substantially nullify the above sources of error.

In presenting our results below we use precipitation (snowfall plus rainfall), rather than accumulation, which has various usages in the literature (sometimes including or excluding rainfall, evaporation, and/or wind-blown snow). In addition, we use the term "runoff" to imply that part of the local surface melt and rainfall on bare ice that escapes according to the refreezing parameterization; "ablation" refers to the escaped runoff plus evaporation; and "mass balance" is the net surface budget (precipitation minus ablation). For the areally averaged ice-sheet budgets reported below, we compute averages over the Laurentide and Cordilleran ice sheet separately, taking the view that they remained dynamically distinct through the LGM. Greenland is also reported as a distinct ice sheet, divided from the Laurentide by a line running north-northeast between Ellesmere Island and Greenland, and not including Iceland (Ellesmere Island and the rest of the Canadian Archipelago are considered part of the Laurentide). Budgets for the Eurasian ice sheet do not include the separate ICE-4G British and Siberian ice sheets, and similarly budgets for Antarctica do not include the separate ICE-4G Patagonian (southern Andes) and New Zealand ice sheets. However, the "global" averages below include all ice-sheet surfaces in the model including the minor ice masses.

\section{With ICE-4G ice sheets}

Figures 1 and 2 show annual precipitation, ablation and net balance fields at the LGM for the ICE-4G ice sheets, with prescribed SSTs (Fig. 1) and predicted SSTs (Fig. 2). The 
a

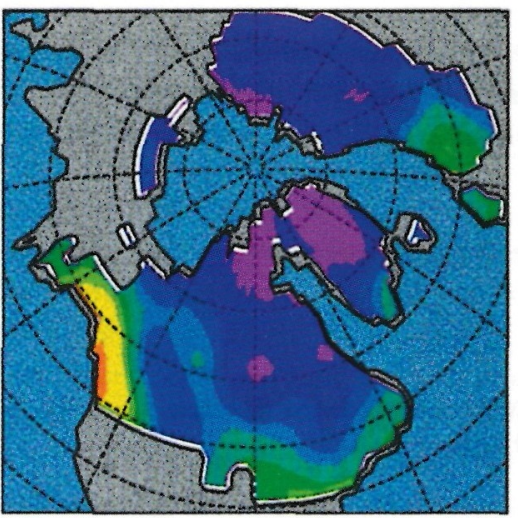

b

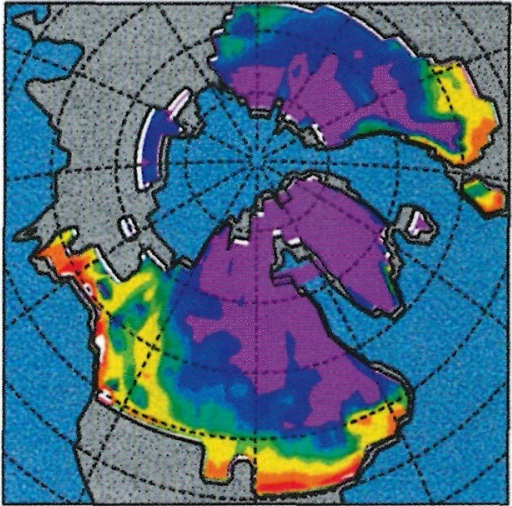

c

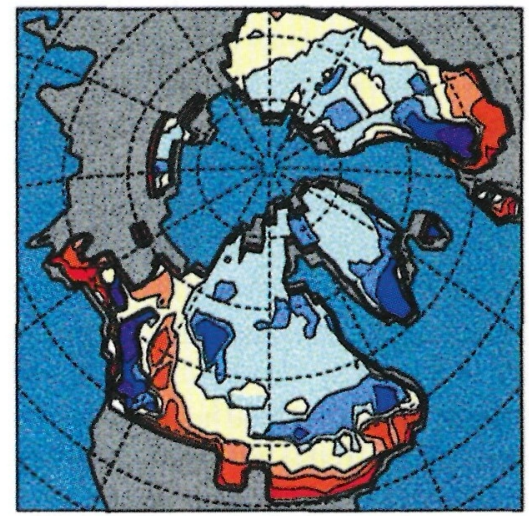

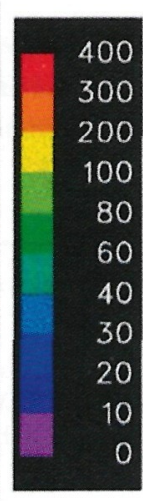

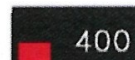

300

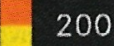

100

80

60

40

30

20

10
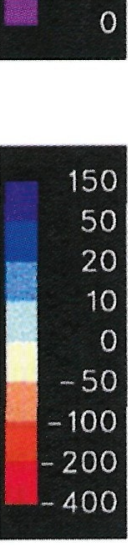

a
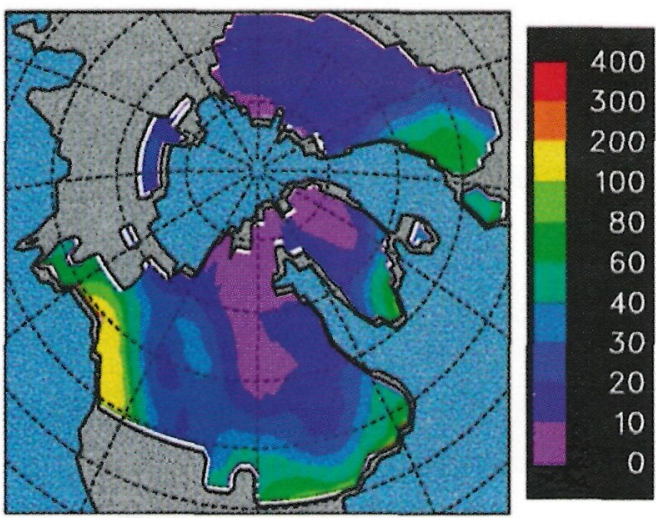

b
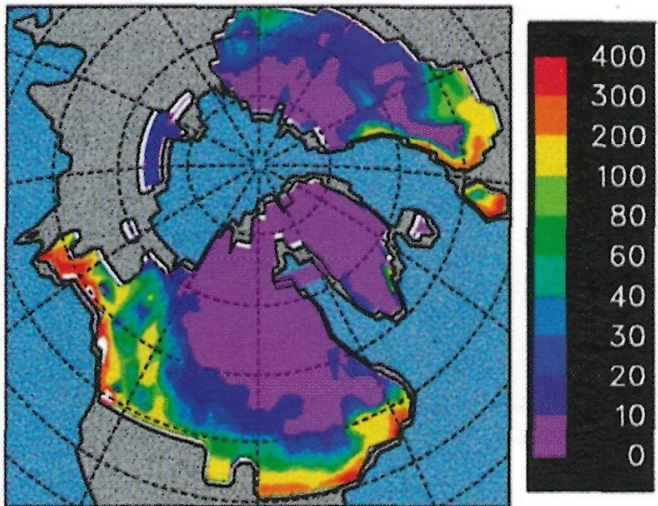

c
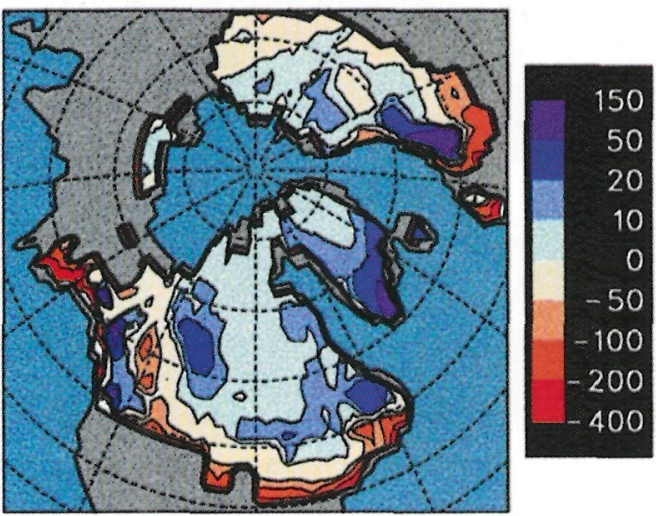

Fig. 1. Ice-sheet surface mass-budget terms over Northern Hemispheric ice sheets for $21 \mathrm{ka} \mathrm{BP}$, in $\mathrm{cm} \mathrm{a}^{-1}$, with ICE-4G ice sheets and prescribed SSTs and sea ice. (a) Annual precipitation. (b) Annual ablation (surface melt and rainfall that escapes the ice sheet, plus evaporation). (c) Net annual surface budget (precipitation minus ablation).

fields are similar for the two types of simulations, as might be expected from the similarity of the temperature and precipitation changes over land (Pollard and Thompson, in press). For the Laurentide, the largest precipitation of 50$100 \mathrm{~cm} \mathrm{a}^{-1}$ occurs on the southern flanks. Higher values of $100-200 \mathrm{~cm} \mathrm{a}^{-1}$ occur on the western flank of the Cordilleran ice sheet, presumably due to orographic uplift of the westerlies, and this causes a "shadow" region of reduced precipitation on the western Laurentide. Precipitation rates over the higher Laurentide interior are much lower, ranging from $\sim 5-30 \mathrm{~cm} \mathrm{a}^{-1}$. There is also very little ablation in most of the interior (Figs $1 \mathrm{~b}$ and $2 \mathrm{~b}$ ). Around the much lower southern flanks, however, several meters of ice melt each year. This is reflected in the net mass balance (Figs lc and 2c), with positive values of up to $\sim 50 \mathrm{~cm} \mathrm{a}^{-1}$ over most of the interior, and much larger negative values around the southern and western flanks and in the Cordilleran-Laurentide divide.

\section{Fig. 2. As Figure 1, except with predicted SSTs and sea ice.}

The areal and annual mean surface mass balance for the ICE-4G Laurentide shown in Table 1 is $-17 \mathrm{~cm} \mathrm{a}^{-1}$ (predicted SSTs) or $-31 \mathrm{~cm} \mathrm{a}^{-1}$ (prescribed SSTs), dominated by the melting around the southern flanks. The prescribed SST budget is more negative because of greater total ablation (not shown), which we suspect is due to warmer subtropical CLIMAP SSTs causing slightly warmer surface-air temperatures over the southern flanks. Dividing these budget values into a rough average thickness of the ice sheet $(1600 \mathrm{~m})$, implies time-scales for complete wastage of $\sim 9400$ or 5100 years, respectively. This does not necessarily mean that a hypothetical ice sheet would vanish in exactly that time given our surface forcing; it might do so faster (due to warmer air temperatures as its elevations decrease, and/ or due to additional wastage by iceberg/ice-shelf discharge), or only the low southern flanks might vanish leaving a high central core with steeper edges. But in any case, the geologic, $\delta^{18} \mathrm{O}$ and sea-level records suggest that the LGM ice sheets, and even the peripheral Laurentide lobes, did not begin such major retreats until shortly after the LGM, so at first sight these overall surface budgets for the LGM Laurentide are much too negative. This will be discussed further in the next section. 
Table 1. Ice-sheet annual mean net surface mass balances in $\mathrm{g} \mathrm{cm}^{-2} a^{-1}$ (or $\mathrm{cm} a^{-1}$ of liquid water equivalent), for the present and $21 \mathrm{ka} \mathrm{BP}$, and for various model runs with prescribed and predicted SSTs and different ice-sheet reconstructions. The last row excludes the relatively small British, Siberian, Patagonian, New Zealand and Iceland ice sheets from the global average. Standard deviations due to inter-annual variability (not shown) are mostly 5-10\% of the mean values, so the resultant uncertainties in the multi-year means are relatively small

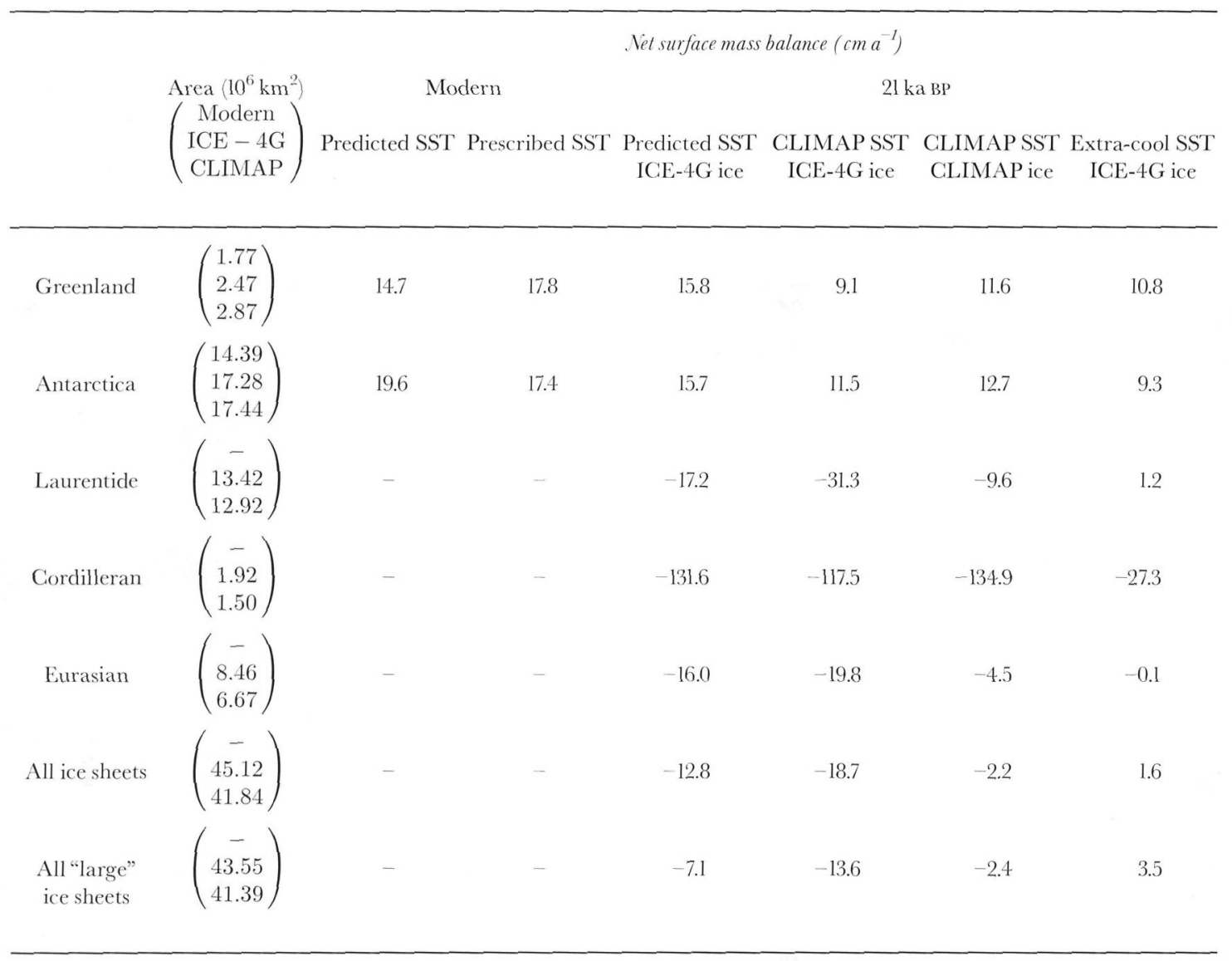

The annual surface mass balance for the ICE-4G Cordilleran ice sheet is $-131 \mathrm{cma}^{-1}$ (predicted SSTs) or $-117 \mathrm{~cm} \mathrm{a}^{-1}$ (prescribed SSTs). Conceivably some surface loss could have been balanced by ice flow from the Laurentide, since the extent of coalescence of the Laurentide and Cordilleran ice sheets at LGM is not well known (Denton and Hughes, 1981). Even with this caveat, we consider such large negative Cordilleran budgets to be very unrealistic (see below).

The patterns of precipitation, ablation and mass balance on the Eurasian ice sheet at LGM are quite similar to those on the Laurentide (Figs 1 and 2). Relatively large amounts of precipitation fall on the southwestern flanks, presumably due to orographic uplift of the westerlies, and several meters of ice melts each year around the southern and western flanks. The overall annual budget (Table 1) is $-16 \mathrm{~cm} \mathrm{a}^{-1}$ (predicted SSTs) or $-20 \mathrm{~cm} \mathrm{a}^{-1}$ (prescribed SSTs). Dividing these into a rough average thickness of the ice sheet $(900 \mathrm{~m})$, the implied time-scales for complete wastage are $\sim 5000$ years.

Since the $\delta^{18} \mathrm{O}$ and eustatic sea-level records represent variations of global ice volume, it is of interest to examine the budgets of the other major ice sheets in the model. For Greenland, the net annual surface budget is $+16 \mathrm{~cm} \mathrm{a}^{-1}$ (predicted SSTs) or $+9 \mathrm{~cm} \mathrm{a}^{-1}$ (prescribed SSTs), quite close to the model's present-day values of +15 or $+18 \mathrm{~cm} \mathrm{a}^{-1}$, although the LGM precipitation and ablation are both much reduced in magnitude from the present. The positive Greenland regime, compared to the negative ICE-4G Laur- entide and Eurasian values, is due to the more northern location of Greenland, and also to its much steeper flanks and consequently much narrower ablation zones.

The net surface budget for Antarctica at the LGM is $+16 \mathrm{~cm} \mathrm{a}^{-1}$ (predicted SSTs) or $+12 \mathrm{~cm} \mathrm{a}^{-1}$ (prescribed SSTs), compared to the model's present-day values of +20 and $+17 \mathrm{~cm} \mathrm{a}^{-1}$. This is due to slightly less LGM precipitation, as might be expected due to the reduced global hydrological cycle compared to the present. This is not necessarily in conflict with the greater size of Antarctica at the LGM deduced from observations (e.g. Denton and Hughes, 1981), which is controlled more by sea level, grounding-line locations and ice-shelf discharge rates, and not by the overall surface budget.

Averaged globally for all model LGM ice-sheet surfaces, the annual budget is $-12.8 \mathrm{cma}^{-1}$ (predicted SSTs) or $-18.7 \mathrm{~cm} \mathrm{a}^{-1}$ (prescribed SSTs) over a total land-ice area of $45.1 \times 10^{6} \mathrm{~km}^{2}$. The first value corresponds to a global eustatic sea-level rise of $1.6 \mathrm{~cm} \mathrm{a}^{-1}$. The relatively small British, Siberian, Patagonian and New Zealand ICE-4G ice sheets have very negative annual budgets in our model (for instance, the Patagonian budget is about $\left.-300 \mathrm{~cm} \mathrm{a}^{-1}\right)$, which are possibly spurious due to the inability of our $2^{\circ} \times 2^{\circ}$ surface grid to resolve some of their structures. Excluding those ice sheets (and Iceland) from the global averages, the net sea-level rise with predicted SSTs is still $0.86 \mathrm{~cm} \mathrm{a}^{-1}$. These rates ignore any basal melt, iceberg and ice-shelf discharge, which would of course add to the sealevel rise. They are similar to the overall observed rate during the last deglaciation from $\sim 17-7 \mathrm{ka} B P$ and, accord- 
ing to the rationale presented in the introduction, they suggest that either the GCM physics or one or more of the major prescribed LGM boundary conditions (ice sheets, SSTs, atmospheric $\mathrm{CO}_{2}$ levels, or orbital elements), are seriously in error. The fact that we obtain similar results with both prescribed CLIMAP SSTs, and a slab mixed-layer ocean, suggests that SSTs are not the problem, although we cannot rule out the possibility that both sets of SSTs are coincidentally too warm. In the mixed-layer case this may be due to the absence of explicit ocean-gyral and thermohaline-circulation changes.

As in all GCM paleoclimate simulations, the possibility of large errors in the GCM physics certainly exists. But, as mentioned in the introduction, exactly the same GCM with the ice-sheet-specific corrections described above produces realistic budgets for present-day Greenland and Antarctica. This leads us to suppose, at least temporarily, that the GCM is substantially correct, and to explore the possibility of error in the boundary datasets.

\section{With GLIMAP ice sheets}

If our GCM climate and the surface budgets of the ICE-4G ice sheets at $21 \mathrm{ka}$ BP are even approximately correct, and if their elevations were not much higher in the preceding few thousand years, the Laurentide and Eurasian would never have expanded to anywhere near their observed LGM southern extents; instead they would have been drastically retreating during that time. (Admittedly the Earth's orbit was somewhat more conducive to ice growth prior to $21 \mathrm{ka} B P$, with minima in summer half-year insolation at northern mid-latitudes occurring around 24-26 ka BP. These insolation differences were relatively small; the primary forcing of Northern Hemispheric climate between $\sim 30-20 \mathrm{ka}$ BP was due to the presence of the ice sheets, not insolation variations. However, if our predicted SST experiments were repeated using the $25 \mathrm{ka}$ BP orbit, we suspect that there would be small but noticeable increases in the icesheet mass budgets, which would help the scenario discussed in the next section.

A possible solution to this dilemma is to suppose that the ice elevations were much higher than ICE-4G during some part of the several thousand years leading up to $21 \mathrm{ka}$ BP. As a crude test of this hypothesis, we performed another GCM simulation for $21 \mathrm{ka}$ BP with ice-sheet extents and elevations from the CLIMAP (1981) reconstruction. Although the geographical boundaries of the ICE-4G ice sheets are quite similar to the earlier CLIMAP reconstructions, the ICE$4 \mathrm{G}$ elevations are considerably lower, especially around the southern flanks and on the central plateaus (Fig. 3). The steeper and thicker CLIMAP (1981) reconstruction is based on the assumption of non-deforming beds supporting relatively high basal-shear stresses, as for Greenland and Antarctica today. In contrast, the ICE-4G reconstruction is independent of ice-sheet rheology, and involves time-dependent models of the asthenospheric and lithospheric response to the post-LGM ice loading, and comparison with observed relative sea-level records (Peltier, 1994). There are significant uncertainties in both reconstructions: for CLIMAP, these include the possibility of deforming beds (Clark, 1994, 1995), the assumption of dynamic equilibrium at the LGM, and the possibility of major marine-based ice-sheet segments (Denton and Hughes, 1981); for ICE-4G, the uncertainties include the assumption of complete isostatic a
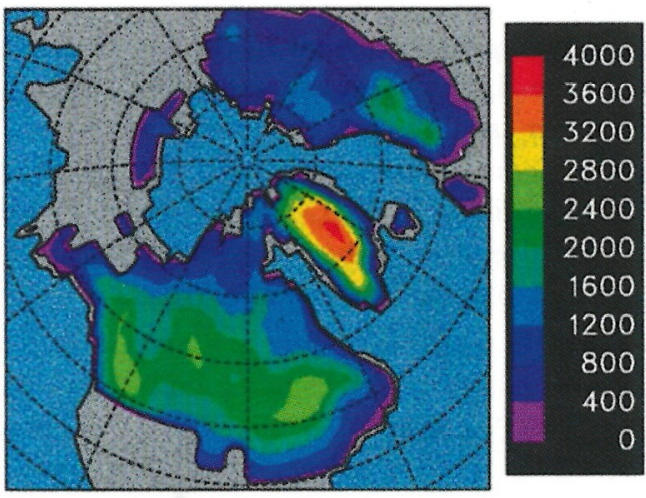

b
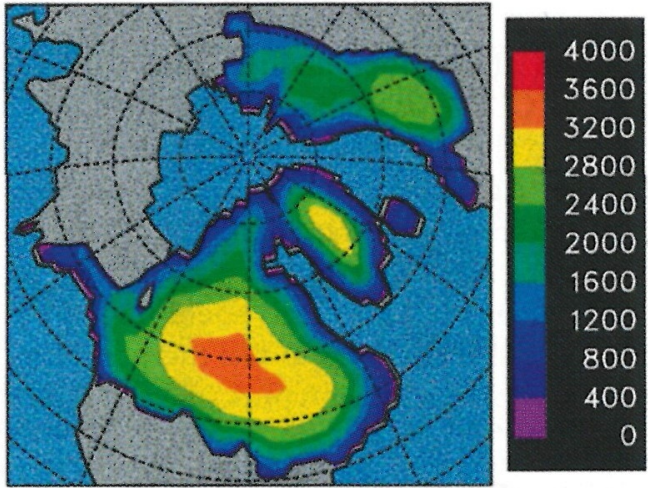

c

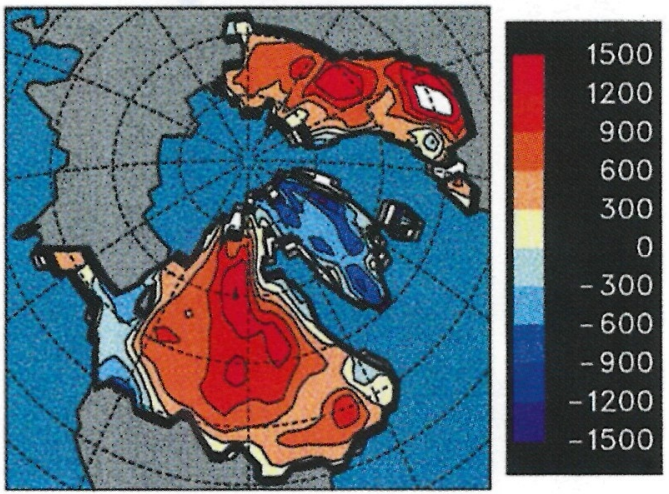

Fig. 3. Ice-sheet topography (before spectral truncation) in $m$ a.s.l. for $21 \mathrm{ka}$ BP Northern Hemispheric ice sheets. (a) ICE-4G ice sheets. (b) CLIMAP ice sheets. (c) Difference (CLIMAP minus ICE-4G).

equilibrium of the bedrock depression at the LGM starting point, and the vertical profile of asthenospheric viscosity (Mitrovica and Davis, 1995).

For our GCM run with CLIMAP ice sheets, SSTs were prescribed from CLIMAP as described above and, except for the ice sheets, the run was identical to the prescribed SST ICE-4G LGM simulation. Figure 4 shows the resulting budgets over the CLIMAP ice sheets. The southern zones of high ablation on the major Northern Hemispheric ice sheets are considerably narrower than for ICE-4G, except for the Cordilleran, the CLIMAP budget of which is even more negative, since its elevations are lower than for ICE-4G. Unlike ICE-4G, there is no obvious "shadow" effect of the CLIMAP Cordilleran on the western Laurentide (in fact, this is a misleading concept since there is no divide separating them in the CLIMAP topography; see Fig. 3b). Despite the higher elevations and steeper flanks, the overall net annual budget for the CLIMAP Laurentide is still $-10 \mathrm{~cm} \mathrm{a}^{-1}$ (Table 1), corresponding to a rough time-scale for complete wastage of 25000 years. This is considerably less negative than the ICE-4G prescribed-SST value of $-31 \mathrm{~cm} \mathrm{a}^{-1}$, but still seems implausible, since it implies that 
the model would not allow a CLIMAP-like Laurentide to expand to its maximum extent in the few thousand years preceding the LGM. For the CLIMAP Eurasian, the annual budget is $-5 \mathrm{~cm} \mathrm{a}^{-1}$ (wastage time-scale $\sim 20000$ years), again considerably less negative than for ICE-4G but still implausible for the LGM. Averaged globally over all CLIMAP ice sheets, the mean budget is $-2.2 \mathrm{~cm} \mathrm{a}^{-1}$, corresponding to a sea-level rise of $0.26 \mathrm{~cm} \mathrm{a}^{-1}$.

\section{With extra SST cooling}

As mentioned above, the validity of the relatively small cooling of the CLIMAP tropical SSTs at the LGM, and the warm pools in the subtropical Pacific, have been brought into question (e.g. Rind and Peteet, 1985; Guilderson and others, 1994; Broccoli and Marciniak, 1996). If the real tropical and subtropical SSTs were indeed several degrees colder than CLIMAP at the LGM, this could have a significant effect on the ice-sheet budgets. To test this possibility we ran an additional experiment, with prescribed SSTs modified at a

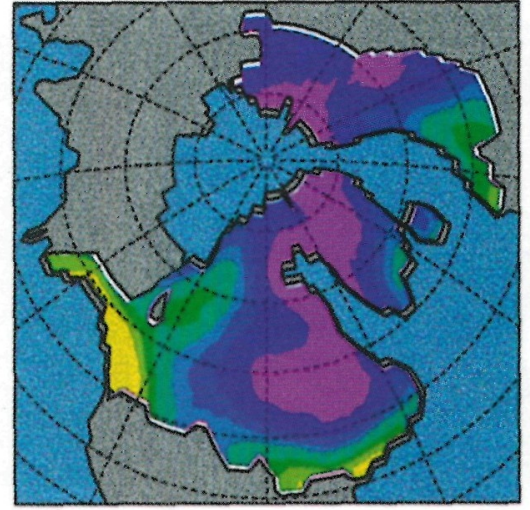

b

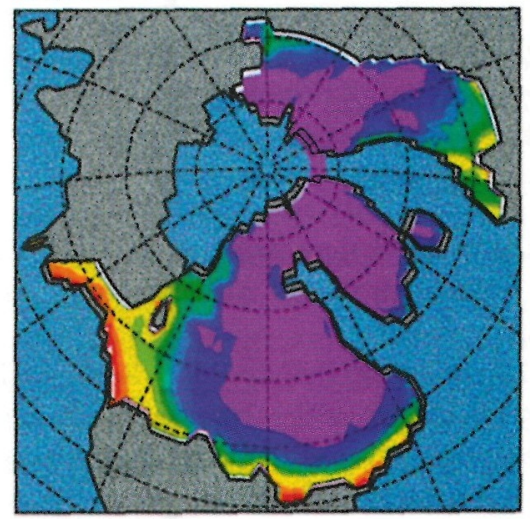

c

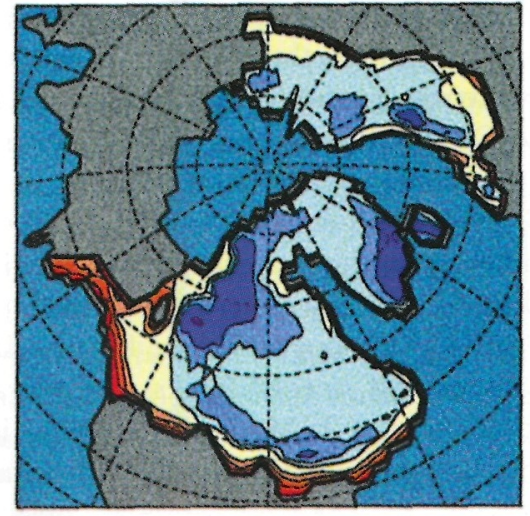

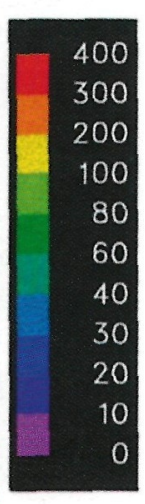

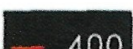

300

200

100

80

60

40

30

20

10

0
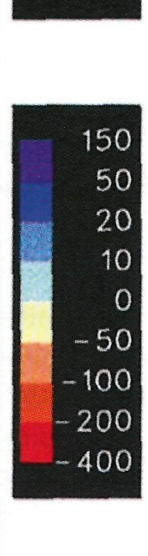

Fig. 4. As Figure 1 except with CLIMAP ice sheets. each gridpoint and month to be at least $6^{\circ} \mathrm{C}$ cooler than present:

$$
T=\min \left(T_{\text {climap }} ; T_{\text {modern }}-6\right)
$$

where $T_{\text {climap }}$ is the monthly SST interpolated from CLIMAP as described above, and $T_{\text {modern }}$ is the monthly present-day climatological SST from Shea and others (1992). This SST modification (personal communication from S. Lehman, 1995) roughly represents the extreme cold end of the envelope of recent data and speculation on LGM SSTs. Sea-ice extents and thicknesses were unchanged from the other prescribed-SSTexperiments described above, and ice sheets were specified from the ICE-4G reconstruction. This run was only 5 years long, with results averaged over the last 3 years. The resulting annual mean surface budgets of the Laurentide, Eurasian and Cordilleran ice sheets are $+1.2,-0.1$ and $-27.3 \mathrm{~cm} \mathrm{a}^{-1}$, respectively (Table 1), thus achieving our "goal" of nearly zero or positive budgets for two out of the three major LGM ice sheets.

However, the magnitude of the imposed SST cooling is extreme, beyond that found by Guilderson and others (1994), and not supported by the results of our predicted SST experiment. Also, the net annual heat flux from the atmosphere to the ocean in the extra-cooling experiment (implicit since SSTs and sea ice are prescribed) is $9.7 \mathrm{~W} \mathrm{~m}^{-2}$, which would warm the whole ocean by about $19^{\circ} \mathrm{C}$ in 1000 years (!), implying that such cold SSTs could not possibly have existed in conjunction with our simulated LGM climate. For these reasons we are led to discount large reductions in low-latitude SSTs (beyond those in our simple slab ocean model, perhaps due to vastly increased oceanheat transport) as a dominant means of achieving positive LGM ice-sheet mass balances in our model.

\section{DISGUSSION}

The central question posed by these ice-sheet budget results is: how could the Laurentide and Eurasian ice sheets have grown out to their maximum observed LGM extents in the interval from about 25-21 ka BP, given the large negative overall budgets simulated by our model for both CLIMAP and IGE-4G ice sheets and for both prescribed CLIMAP and predicted SSTs? One immediate answer is of course that the GCM climate is in error. This is a real possibility, and we will pursue that in the future; also it will be tested as other modern high-resolution GCMs are applied to this problem.

Some of the main uncertainties in the present model are discussed in Pollard and Thompson (in press). However, as discussed in that paper, the $21 \mathrm{ka} \mathrm{BP}$ climate of the model compares favorably to a number of other proxy data. And our two current ice-sheet-specific techniques, that correct the relatively coarse-grid GGM meteorology to the icesheet surface, and account for the GCM's neglect of meltwater refreezing, do yield realistic mass balances for present-day ice sheets (Thompson and Pollard, 1997). That gives us the temerity to imagine (at least for the remainder of this paper) that the GCM physics is more or less correct, and to explore the consequences of our negative LGM icesheet budgets in terms of the prescribed boundary datasets and the basic rationale itself of non-negative budgets at the LGM.

We have only been able to achieve a near-zero ICE-4G Laurentide budget with an unreasonably large imposed cooling of SSTs. Using CLIMAP SSTs and CLIMAP ice 
sheets, the Laurentide budget is still slightly negative $\left(-10 \mathrm{~cm} \mathrm{a}^{-1}\right)$, but we expect that a further simulation with moderate additional cooling from aerosols* (Harvey, 1988; but see Anderson and Charlson, 1990), combined with CLIMAP ice sheets and predicted mixed-layer SSTs could yield zero or positive ice budgets, and we are currently preparing to make such a run. Assuming that expectation is true and, if a CLIMAP-like Laurentide ice sheet existed from $\sim 25$ $22 \mathrm{ka} \mathrm{BP}$, it could have grown out to the observed southern boundaries at the LGM. But in order to be consistent with the ICE-4G reconstruction at $21 \mathrm{ka} \mathrm{BP}$, such an ice sheet would have had to undergo rapid collapse to the ICE-4G profile just before $21 \mathrm{ka} \mathrm{BP}$.

Is this scenario physically possible? Such a collapse is similar to the surges over deformable thawed beds proposed by MacAyeal (1993), Clark (1994, 1995) and others. Clark has suggested that surging of the southern periphery of the Laurentide occurred repeatedly during and since the LGM, due to the sedimentary beds underlying the southern parts of the ice sheet south of the Canadian Shield. Surges occurred when these beds warmed to the melting point and became lubricated; at other times they were frozen and could support higher basal-shear stress. So from 25-22 ka BP these southern beds could have been frozen and able to support the steep flanks of a CLIMAP-like ice sheet, and could have become lubricated at about $21 \mathrm{ka} \mathrm{BP}$ and induced a sudden collapse of the ICE- $4 \mathrm{G}$ profile. Immediately following the surgeinduced collapse, the southern portions of the ICE-4G Laurentide would have experienced rapid ablation, and the southern margins would have begun to retreat rapidly.

Is this scenario in obvious conflict with the geologic record? The collapse of such a large volume of ice, if it had flowed into the Gulf of Mexico, should have left a freshwater signal in $\delta^{18} \mathrm{O}$ and planktonic foraminifera cores in that region, but no such spikes are evident during that period (Kennett and Shackleton, 1975). However, if most flowed into the North Atlantic, that would coincide with Heinrich Event H2 (Bond and others, 1993; Broecker, 1994). Global ice-volume records determined from $\delta^{18} \mathrm{O}$ cores show a single global ice-volume maximum at $21 \mathrm{ka} \mathrm{BP}$; however, these represent the combined contributions of other ice sheets (notably Antarctica), and the exact timing of the last maximum is smeared by at least 1000-2000 years due to bioturbation. Hence the true maximum volume of the Laurentide could have occurred slightly earlier than $21 \mathrm{ka}$ BP. High-resolution eustatic sea-level curves should have recorded a sudden sea-level rise of several tens of meters corresponding to the difference in the CLIMAP and ICE4G Laurentide volumes, but, to date, such records only extend back to about 21 ka BP (Fairbanks, 1989).

The terrestrial evidence of the margins of the Laurentide are not as well dated as the deep-sea cores, but do suggest the possibility of complex behavior around the LGM; for instance, measured dates of maximum advance or initial retreat vary between $24-14 \mathrm{ka}{ }^{14} \mathrm{C}$ around the southern and western margins (Ruddiman and Wright, 1987; Clark, $1994)^{\dagger}$. One consequence of this scenario would be to alter

\footnotetext{
* Increased amounts of atmospheric aerosols at the LGM might be a two-edged sword, since although they can cool surface-air temperatures (via their effect over oceans), they can also decrease ice-sheet mass balance by lowering albedos in the ablation zones (Peltier and Marshall, 1995).
}

the initial conditions at $21 \mathrm{ka}$ BP assumed for the ICE-4G reconstruction, which were complete isostatic equilibrium of the bedrock depression under the relatively thin ICE-4G ice sheets (Peltier, 1994). In the above scenario, the initial depression would have been much deeper due to the prior prolonged existence of a much thicker CLIMAP-like ice sheet. Mitrovica and Davis (1995) have shown that similar changes in the assumed initial conditions have significant effects on the subsequent time-dependent ICE-4G results (although they did not analyze the particular scenario suggested here).

The large negative model budgets for the Cordilleran noted above suggest that even with steeper CLIMAP profiles, additional aerosols, and earlier orbits, the Cordilleran could not have grown out to its CLIMAP or ICE-4G extent by $21 \mathrm{ka}$ BP. However, the terrestrial stratigraphic record suggests that the Cordilleran ice sheet was largely non-existent for much of the period from $\sim 60 \mathrm{ka} \mathrm{BP}$ to a few thousand years before the LGM, and did not reach its maximum extent until $15-14 \mathrm{ka}{ }^{14} \mathrm{C}$ years $(18-17 \mathrm{ka} \mathrm{BP}$ ) (Clark and others, 1993). This would explain our predicted negative Cordilleran budgets, but would leave unexplained how the Cordilleran could then have grown to its maximum size between 21-17 ka BP, while the Laurentide was retreating. (The "shadowing" effect of the ICE-4G Cordilleran noted above suggests that a much smaller Cordilleran prior to $21 \mathrm{ka}$ BP could have allowed more snowfall from the moist westerlies to reach the western and southwestern flanks of the Laurentide, thus aiding the latter's growth to the LGM, and that subsequent growth of the Cordilleran after the LGM could have accelerated retreat of the Laurentide's western sectors (personal communication from P. Clark, 1996).)

We propose the above scenario tentatively, as a possible starting point for exploration of conditions leading up to the LGM. Given the uncertainties inherent in any paleoclimatic GCM simulation, it would be foolhardy to take our simulated negative-ice budgets at face value. But if they do turn out to be robust, and are confirmed by independent GCM simulations in the future (with higher resolutions, and/or using similar ice-sheet-specific correction techniques to those above), then the question will remain: how could the Laurentide and Eurasian ice sheets have expanded to their maximum extents in the few thousand years leading up to the LGM? Based on the scenario suggested above, we plan to perform additional GCM experiments with (i) additional aerosols, (ii) $25 \mathrm{ka}$ BP orbit, (iii) CLIMAP ice-sheet profiles, and (iv) a lowered or non-existent Cordilleran ice sheet to reduce its "shadow" effect on the Laurentide precipitation. If these experiments produce positive mass balances, then it would be worthwhile to perform an asynchronous run spanning the interval $\sim 30-21 \mathrm{ka} \mathrm{BP}$, with the GCM coupled to a 2-D dynamical ice-sheet model (Pollard and Thompson, 1997; Schlesinger and Verbitsky, 1996).

$\dagger$ If significant retreat of the Laurentide margins did not begin until $15 \mathrm{ka}{ }^{14} \mathrm{C}$ years $(\sim 17 \mathrm{ka} \mathrm{BP})$, perhaps the transition from CLIMAP to ICE-4G profiles could have occurred gradually or episodically from $21-17 \mathrm{ka}$ BP, instead of as a single event at $21 \mathrm{ka}$ BP. But the former would conflict more with the initial part of the ICE-4G deglaciation history (Peltier, 1994). 


\section{ACKNOWLEDGEMENTS}

We thank P. Clark (Department of Geosciences, Oregon State University, Corvalis, U.S.A.) for helpful debate on much of the material in the discussion, including the idea of a smaller Cordilleran ice sheet allowing more precipitation onto the western Laurentide and vice versa. Thanks are due to S. Lehman (INSTAAR, University of Colorado, Boulder, U.S.A.) for suggesting the cooler "tapered SST" experiment, and to him and others at INSTAAR for a helpful discussion on LGM ice-sheet budgets. We also thank E. Barron and D. Rind for careful reviews and comments that improved the manuscript. The development of the GENESIS Earth systems model at NCAR is supported in part by the U.S. Environmental Protection Agency Interagency Agreement DW49935658-01-0. The National Center for Atmospheric Research is sponsored by the National Science Foundation.

\section{REFERENCES}

Anderson, T. L. and R. J. Charlson. 1990. Ice-age dust and sea salt. Nature, $345(6274), 393$.

Bard, E., B. Hamelin, R.G. Fairbanks and A. Zindler. 1990. Calibration of the ${ }^{14} \mathrm{C}$ time-scale over the past 30,000 years using mass spectrometric U-Th ages from Barbados corals. Nature, 345 (6274), 405-410.

Berger, A. 1978. Long-term variations of daily insolation and Quaternary climatic changes. 7. Atmos. Sci., 35(12), 2362-2367.

Bond, G. and 6 others. 1993. Correlations between climate records from North Atlantic sediments and Greenland ice. Nature, 365(6442), 143-147.

Broccoli, A. J. and S. Manabe. 1993. Climate model studies of interactions between ice sheets and the atmosphere-ocean system. In Peltier, W. R., ed. Ice in the climate system. Berlin, etc., Springer-Verlag, 271-290. (NATO ASI Series I: Global Environmental Change 12.)

Broccoli, A.J. and E. P. Marciniak. 1996. Comparing simulated glacial climate and paleodata: a re-examination. Paleoceanography, 11 (1), 3-14.

Broecker, W. S. 1994. Massive iceberg discharges as triggers for global climate change. Nature, 372 (6505), 421-424.

Clark, P. U. 1994. Unstable behavior of the Laurentide ice sheet over deforming sediment and its implications for climate change. Quat. Res., $41(1), 19-25$.

Clark, P. U. 1995. Fast glacier flow over soft beds. Science, 267(5194), 43-44.

Clark, P. U. and 15 others. 1993. Initiation and development of the Laurentide and Cordilleran ice sheets following the last interglaciation. Quat. Sci. Rev., 12(2), 79-114.

CLIMAP Project Members. 1981. Seasonal reconstructions of the Earth's surface at the last glacial maximum. Boulder, CO, Geological Society of America. (Map Chart MC-36.)

Denton, G. H. and T.J. Hughes, eds. 1981. The last great ice sheets. New York, etc., John Wiley and Sons.

Dyke, A. S. and V. K. Prest. 1987. Late Wisconsinan and Holocene history of the Laurentide ice sheet. Géogr. Phys. Quat., 41(2), 237-263.

Fairbanks, R. G. 1989. A 17,000-year glacio-eustatic sea level record: influence of glacial melting rates on the Younger Dryas event and deepocean circulation. Nature, 342 (6250), 637-642.

Flato, G. M. and W. D. Hibler, III. 1992. Modeling pack ice as a cavitating fluid. 7. Phys. Oceanogr., 22(6), 626-651.

Guilderson, T. P., R. G. Fairbanks and J. L. Rubenstone. 1994. Tropical temperature variations since 20,000 years ago: modulating interhemispheric climate change. Science, 263, 663-665.

Harvey, L. D. D. 1988. Climatic impact of ice-age aerosols. Nature, 334(6180), 333-335.

Hyde, W. T. and W. R. Peltier. 1993. Effect of altered boundary conditions on GCM studies of the climate of the last glacial maximum. Geophys. Res. Lett., $20(10), 939-942$

Imbrie, J. and 8 others. 1984. The orbital theory of Pleistocene climate: support from a revised chronology of the marine $\delta^{18} \mathrm{O}$ record. In Berger, A., J. Imbrie, J. Hays, G. Kukla and B. Saltzman, eds. Milankovitch and climate: understanding the response to astronomical forcing. Part 1. Dordrecht, etc., D. Reidel Publishing Co., 269-305. (NATO ASI Series C: Mathematical and Physical Sciences 126.)

Joussaume, S., R. S. Webb and K. Taylor. 1993. The Paleoclimate Modelling Intercomparison Project (PMIP). In Anderson, D.M., ed. Global paleoenvironmental data: a report from the workshop sponsored by Past Global Changes (PAGES), August 1993. Bern, International Geosphere-Biosphere Programme, 97-100.

Kennett, J. P. and N. J. Shackleton. 1975. Laurentide ice sheet meltwater recorded in Gulf of Mexico deep-sea cores. Science, 188(4184), 147-150.

MacAyeal, D. R. 1993. Binge/purge oscillations of the Laurentide ice sheet as a cause of the North Atlantic's Heinrich events. Paleoceanography, 8 (6), $775-784$.

Manabe, S. and A. J. Broccoli. 1985. The influence of continental ice sheets on the climate of an ice age. 7. Geophys. Res., 90(D1), 2167-2190.

Meier, M. F. 1993. Ice, climate, and sea level: do we know what is happening? In Peltier, W. R., ed. Ice in the climate system. Berlin, etc., Springer-Verlag, 141-160. (NATO ASI Series I: Global Environmental Change 12.)

Mitrovica, J. X. and J. L. Davis. 1995. The influence of a finite glacial phase on predictions of post-glacial isostatic adjustment. Earth Planet. Sci. Lett., 136, 343-361.

Peltier, W. R. 1994. Ice age paleotopography. Science, 265(5169), 195-201.

Peltier, W. R. and S. Marshall. 1995. Coupled energy-balance/ice-sheet model simulations of the glacial cycle: a possible connection between terminations and terrigenous dust. 7. Geophys. Res., 100 (D7), 14,269-14,289.

Pfeffer, W. T., M. F. Meier and T. H. Illangasekare. 1991. Retention of Greenland runoff by refreezing: implications for projected future sea level change. J. Geophys. Res., 96 (C12), 22,117-22,124.

Pollard, D. and S. L. Thompson. 1994. Sea-ice dynamics and $\mathrm{CO}_{2}$ sensitivity in a global climate model. Atmosphere-Ocean, 32 (2), 449-467.

Pollard, D. and S. L. Thompson. 1995. Use of a land-surface-transfer scheme (LSX) in a global climate model: the response to doubling stomatal resistance. Global and Planetary Change, 10, 129-161.

Pollard, D. and S. L. Thompson. 1997. Driving a high-resolution dynamic ice-sheet model with GCM climate: ice-sheet initiation at $116000 \mathrm{BP}$. Ann. Glaciol., 25 (see paper in this volume).

Pollard, D. and S.L. Thompson. In press. Climate and ice-sheet mass balance at the last glacial maximum from the GENESIS version 2 global climate model. Quat. Sci. Rev.

Rind, D. 1987. Components of the ice age circulation. F. Geophys. Res, 92(D4), 4241-4281.

Rind, D. and D. M. Peteet. 1985. Terrestrial conditions at the last glacial maximum and CLIMAP sea-surface temperature estimates: are they consistent? Quat. Res., 242(1), 1-22.

Ruddiman, W. F. and H. E. Wright, Jr, eds. 1987. North America and adjacent oceans during the last deglaciation. Boulder, CO, Geological Society of America. (The Geology of North America Vol. K-3.

Schlesinger, M. E. and M. Verbitsky: 1996. Simulation of glacial onset with a coupled atmosphere general circulation/mixed-layer ocean-icesheet/asthenosphere model. Paleoclimates, 2, 179-201.

Shackleton, N. J. 1987. Oxygen isotopes, ice volume and sea level. Quat. Sci. Rev., 6(3-4), 183-190.

Shea, D. J., K. E. Trenberth and R. W. Reynolds. 1992. A global monthly sea surface temperature climatology. F. Climate, 5(9), 987-1001.

Thompson, S. L. and D. Pollard. 1995a. A global climate model GENESIS) with a land-surface-transfer scheme (LSX). Part l. Present-day climate. f. Climate, 8, 732-761.

Thompson, S. L. and D. Pollard. 1995b. A global climate model (GENESIS) with a land-surface-transfer scheme (LSX). Part 2. $\mathrm{CO}_{2}$ sensitivity. 7. Climate, 8, 1104-1121.

Thompson, S. L. and D. Pollard. 1997. Greenland and Antarctic mass balances for present and doubled atmospheric $\mathrm{CO}_{2}$ from the GENESIS version 2 global climate model. f. Climate, 10, 871-900.

Van der Veen, C. J. 1991. State of balance of the cryosphere. Rev. Geophys., 29 (3), 433-455.

Warrick, R. A. and J. Oerlemans. 1990. Sea level rise. In Houghton, J.T., G. J. Jenkins and J. J. Ephraums, eds. Climate change: the IPCC scientific assessment. Cambridge, Cambridge University Press, 257-281.

Warrick, R. A., C. Le Provost, M. F. Meier, J. Oerlemans and P. L. Woodworth. 1996. Change in sea level. In Houghton, J. T., L. G. Meira Filho, B. A. Callander, N. Harris, A. Kattenberg and K. Maskell, eds. Climate change 1995: the science of climate change. Cambridge, etc., Cambridge University Press, 359-406. 